\title{
Reanudación de la actividad quirúrgica electiva post COVID-19. Rol de la Anestesia Regional En Un proceso Seguro
}

\author{
Elective surgical activity resumption post COVID-19. regional anesthesia role within a safe process
}

https://doi.org/10.25237/carsach2020.02

Dra. Ana María Espinoza U. 1 Dra. Loreto Muñoz B. ${ }^{1}$

${ }^{1}$ Servicio de Anestesiología Clínica Alemana de Santiago Chile

Autor Corresponsal:

Dra. Ana María Espinoza U.

aespinozau@alemana.cl

ORCID ID: https://orcid.org/0000-0002-0590-6886

Palabras claves:

Anestesia, reanudación, cirugía electiva, peri-operatorio, COVID -19, SARS CoV-2, morbilidad, mortalidad

Key words:

Anesthesia, recovery, elective surgery, peri-opearative, COVID_19, SARS CoV-2, morbidity and mortality

\section{Puntos Clave}

- La reanudación de la cirugía electiva en pandemia, requiere de un nuevo enfrentamiento clínico. Debemos seguir evitando contagios en una situación de máximo rendimiento y política de contención de costos.

- Para obtener buenos resultados, los protocolos de reanudación deberían considerar características de los pacientes, de la cirugía, de las instituciones y del contexto epidemiológico local.

- El nuevo escenario contempla en forma simultánea tres grupos de pacientes: pacientes sanos, pacientes Covid-19 falsos negativos, pacientes Covid-19 recuperados.

- Los pacientes Covid-19 recuperados pueden estar sanos o tener condiciones que requieran precaución y definición del momento más oportuno para ir a cirugía.

- En este contexto que nos exige seguridad, rendimiento y contención de costos, la anestesia regional es una gran herramienta.

\section{Resumen}

La pandemia por SARS COV2 obligó a postergar la cirugía electiva por meses. Hoy nos enfrentamos al desafío de reanudar dicha cirugía, en forma segura tanto para los pacientes como para el personal médico. El escenario quirúr- 
gico nos exige dar solución en forma simultánea a pacientes COVID-19 recuperados, pacientes COVID-19 activos (sintomáticos o no) y pacientes sin infección. La literatura disponible sugiere desarrollar protocolos institucionales considerando el tipo de población, tipo de cirugía y características particulares de cada hospital. Los esfuerzos deben centrarse no sólo en evitar contagios y obtener buenos resultados en términos de morbimortalidad, sino que adicionalmente nos vemos obligados a optimizar al máximo el rendimiento en pabellón junto a una política de contención de costos. En este sentido la anestesia regional neuroaxial y los bloqueos periféricos constituyen una alternativa de enfrentamiento anestésico y analgésico muy favorable.

\begin{abstract}
SARS COV-2 pandemic forced medical teams to delay elective surgery several months. Today we face the challenge of resuming these surgeries, in a safe way for both patients and for medical team. Surgical stage demands simultaneous solutions for recovered COVID-19 patients, active COVID-19 patients (with or without symptoms) and patients with no infection at all. Available literature suggests developing institutional protocols, depending on population type, surgery type and specific features of each hospital. Efforts must be focused not only in avoiding contagions and getting good outcomes in terms of morbidity and mortality, but we also are forced to optimize to the extreme the OR performance along with a cost containment policy. Considering all these factors, regional neuraxial anesthesia and peripheral nerve blocks offer a very favorable option for anesthetic and analgesic management.
\end{abstract}

\title{
Introducción
}

El brote pandémico de SARS-COV2 (COVID-19) nos plantea desafíos en forma permanente, a una velocidad mayor a la habitual y nos obliga a incorporar conductas y a tomar decisiones en base a evidencia de diferente calidad, no necesariamente óptima.

La pandemia llevó a los sistemas de salud a reducir casi en su totalidad el número de cirugías electivas, como también a postergar la atención y control periódico de pacientes con patologías crónicas, para poder privilegiar la atención de pacientes COVID, reservar recursos para financiar equipos de protección personal y evitar contagios (1).

Han pasado 6 meses desde el inicio de la pandemia en nuestro país y a la fecha existen más de 400.000 casos reportados y más de 10.000 muertes confirmadas por COVID 19 (2). Lo anterior nos enfrentará a un escenario diferente en que deberemos dar solución sanitaria a los casos nuevos y a los pacientes postergados, muchos de los cuales llegarán a pabellón con un peor control de sus patologías de base. En el campo de la cirugía ortopédica además enfrentaremos pacientes con más dolor e impotencia funcional, considerando la postergación de sus cirugías por meses, el pobre control del dolor y la imposibilidad de realizar actividad física y rehabilitación formal.

Este nuevo escenario, además posee la particularidad de incluir tres tipos de pacientes desde el punto de vista epidemiológico. Aquellos que no han tenido COVID-19, los que están cursando con COVID-19 pero sin diagnóstico(falsos negativos) y por último, los pacientes que se recuperaron de una infección por COVID-19. El primer grupo de pacientes nos motivará a continuar evitando contagios intrahospitalarios, en las diferentes etapas del proceso quirúrgico. El segundo grupo nos significa mantener las políticas generales de protección de contagio COVID-19, más aun, en procedimientos que involucren la vía aérea. Pacientes COVID-19 diagnosticados, no son candidatos a cirugía electiva, aunque tendremos que acostumbrarnos a coexistir con ellos, pero en un flujo paralelo.

El tercer grupo representa un tipo de paciente nuevo, que eventualmente requerirá de anestesia para cirugía electiva. Estos pacientes podrían ser portadores de condiciones clínicas secuelares, que tengan impacto relevante sobre la morbimortalidad y a ellos nos referiremos principalmente.

No debemos olvidar que uno de los problemas centrales es que existe una mayor morbimortalidad en pacientes que se someten a cirugía cursando con COVID-19 o que en el perioperatorio se contagian $(3,4)$ lo que obliga a manejar rigurosas políticas de identificación de pacientes infectados y de aislamiento de los casos positivos, para limitar la aparición de brotes y disminuir las complicaciones. No podemos relajar las medidas de protección dado que los pacientes infectados pueden contagiar siendo asintomáticos, presintomáticos o sintomáticos. 
En el momento actual debemos planificar una reanudación de la cirugía electiva, que nos permita conciliar la seguridad para nuestros pacientes y equipo médico, junto con la eficiencia del sistema y la contención de costos. Nuestros esfuerzos deben apuntar a obtener buenos resultados en salud, optimizando al máximo los sistemas hospitalarios, teniendo flexibilidad en torno a la evidencia disponible y sobre todo a la evolución epidemiológica local.

La literatura recomienda que cada institución genere protocolos de reanudación de cirugía electiva. Tanto para la selección, como para el manejo de los pacientes. Estos protocolos deberían ser flexibles, considerando la evidencia científica disponible junto con la situación epidemiológica local y las particularidades de cada centro, tanto por tipo de población, tipo de cirugía realizada, como por hospitalización simultánea de pacientes COVID-19, disponibilidad de camas de UCI, etc.

El presente artículo se alinea con las recomendaciones publicadas por la Sociedad Chilena de Anestesiología (SACH) previamente (5) y destaca aspectos clínicos que se han ido presentando en este nuevo escenario, intentando dar respuesta a las dudas que surgen frente al COVID-19.

\section{Objetivos}

Facilitar la reanudación progresiva de la cirugía electiva (postergable) en el contexto de la pandemia por COVID-19

Entregar herramientas para que el proceso se desarrolle en forma segura tanto para los pacientes como para el equipo médico

Diferenciar de acuerdo al riesgo actual a los pacientes candidatos quirúrgicos que han tenido COVID-19 en sus diferentes presentaciones

Favorecer la eficiencia del sistema hospitalario y la contención de costos

Llamar la atención sobre las ventajas que presenta la Anestesia Regional bien utilizada en este contexto

\section{Metodología utilizada}

Búsqueda bibliográfica de recomendaciones de sociedades científicas internacionales y nacionales

Búsqueda bibliográfica de artículos relacionados a la enfermedad según palabras clave: anestesia, cirugía electiva, peri-operatorio, COVID -19, SARS CoV-2, morbimortalidad.

Consulta de opinión de expertos de diversas especialidades relacionada a la recomendación.

\section{Momento de reanudación}

La SACH recomienda retomar la actividad quirúrgica electiva cuando exista una reducción significativa y sostenida de los casos nuevos. Además de disponibilidad asegurada de recursos hospitalarios en su más amplia expresión. Se recomienda que sólo los recintos que se encuentren en Fase COVID 0 ó 1 inicien o aumenten la actividad quirúrgica electiva durante la pandemia COVID-19 (5).

\section{Propuesta de reanudación escalonada para pacientes no COVID}

Todas las recomendaciones actuales, plantean además de una adecuada situación país y hospitalaria local, una reanudación escalonada de la cirugía electiva (tabla 1).

Deben considerarse las características propias del paciente, como su edad, comorbilidades y compensación de estas comorbilidades. El tipo de cirugía al que será sometido, que incluye sitio quirúrgico, duración de la cirugía, tamaño del equipo quirúrgico requerido, días de hospitalización necesarios, probabilidad de requerir UCI-intermedio postoperatorio, necesidad de transfusiones y rehabilitación intrahospitalaria postoperatoria. Así como la patología que motiva la cirugía, el impacto de la demora de la cirugía en el resultado y que pueda o no tener opciones no quirúrgicas (6)

En una primera etapa se recomienda favorecer la cirugía electiva que cumpla con criterios de régimen ambulatorio, luego incorporar aquellas de hospitalización acotada (hasta 2 noches), más tarde cirugías que requieran 3-4 días de hospitalización y finalmente aquellas que requieren más de 4 días de hospitalización. Respecto de las características de los pacientes, inicialmente serían candidatos los pacientes adultos menores de 65-70 años y pediátricos mayores de 1 año. Teniendo prioridad pacientes ASA I - II (en presencia de comorbilidad compensada y considerada de bajo riesgo de complicación respiratoria). 
En una etapa inicial NO serán candidatos prioritarios los pacientes con múltiples comorbilidades, IMC sobre 30, portadores de patologías respiratorias crónicas, apnea obstructiva del sueño, pacientes inmunosuprimidos o cardiópatas crónicos. Y en niños se sugiere evitar operar a aquellos con factores de riesgo más relevantes como son la inmunosupresión, obesidad, asma o cardiopatías.

En un segundo momento se podrían incorporar pacientes mayores de 70 años y niños hasta los 6 meses y luego desde 1 mes de vida. Los pacientes ASA III-IV serán los últimos en incorporarse, asegurándose la disponibilidad de todas las unidades de apoyo necesarias (cama UCI/VM) en ambientes separados COVID/No COVID.

Es difícil esquematizar de manera rígida este proceso, puesto que cada centro hospitalario tiene una realidad completamente diferente, pero la $\mathrm{SACH}$ ha presentado una completa guía con recomendaciones que nos pueden orientar en este trabajo (5).

\section{Tabla 1}

\section{Agendamiento}

Se ha sugerido que en la reanudación de la actividad quirúrgica post COVID-19 el agendamiento de cirugías electivas se realice con un mínimo de 72 horas de anticipación, salvo excepciones, para permitir la adecuada implementación de los protocolos de seguridad locales.

\section{Evaluación preoperatoria}

Debe existir una adecuada política de identificación de pacientes en riesgo de ser COVID (+). Una buena herramienta es la encuesta epidemiológica (5), que permite identificar pacientes sospechosos, probables o contactos estrechos. En pediatría, la encuesta la debe responder uno de los padres, familiar o tutor legal.

Cada institución debe definir cómo y cuándo aplicará esta encuesta. El tener una o más respuestas positivas implica la postergación de cualquier cirugía electiva.

Otra herramienta útil y fuertemente recomendada por la Asociación Americana de Anestesiología es el testeo de PCR para identificar pacientes que sean asintomáticos y presintomáticos (7). Lo ideal sería contar con PCR (-) de no más de 72 horas al momento de entrar a pabellón.

Toda vez que se requiera (y se permita) acompañante, éste debe estar asintomático e idealmente tener una PCR negativa tomada hasta 72 horas previo al ingreso.

Actualmente no existe una recomendación de complementar el estudio con serología $\operatorname{IgM}$ e $\operatorname{IgG}$, éstas no son fáciles de interpretar, pueden presentar falsos negativos porque no todos los pacientes desarrollan anticuerpos detectables y también falsos positivos por reacción cruzada con otros coronavirus (8). Utilizarlas requeriría además de un trabajo conjunto y comunicación muy fluida entre los infectólogos locales, IAAS y los equipos de trabajo quirúrgicos.

Entendiendo entonces que estamos frente a pacientes sin síntomas, aquellos con PCR (+) no son candidatos a cirugía electiva. Estos procedimientos deberían postergarse 14 días desde la obtención de la PCR $(+)$.

Considerando que la encuesta y las pruebas de laboratorio no logran pesquizar al $100 \%$ de los pacientes infectados, a todos los pacientes se les debe recomendar aislamiento social preventivo por 7 días previo a la cirugía electiva, porque, aunque el período de incubación puede llegar a ser de 14 días, un $75 \%$ de los pacientes se hace sintomático dentro de los primeros 7 días. Si para el paciente fuese posible, se sugiere hacer este aislamiento por 14 días, lo que permitiría una cobertura del $97.5 \%$ de los pacientes (9). En este momento no existe en Chile un código para entregar licencia médica con este fin.

Pacientes sintomáticos respiratorios de cualquier origen y magnitud NO son candidatos a cirugía electiva aún con PCR negativa.

Cuando sea posible en cada institución, se recomienda una encuesta o evaluación preoperatoria hecha por video conferencia o por vía telefónica, para conocer las patologías de base y su grado de compensación, antes de la hospitalización.

\section{Pacientes COVID recuperados}


El virus SARS COV-2 produce la enfermedad que conocemos como COVID-19. Este coronavirus se transmite de persona a persona a través de contacto directo y gotitas respiratorias. Al llegar al huésped se une al receptor de ECA II (enzima convertidora de angiotensina II), principalmente en neumocitos tipo II, pero también en otras células que poseen el receptor (10). Al unirse al receptor, éste sufre endocitosis y comienza así un proceso que permite replicación viral dentro de la célula y que podría conducir incluso a un cuadro de daño multiorgánico para el que se han propuesto diferentes mecanismos fisiopatológicos: daño viral directo, daño endotelial en diferentes tejidos, desregulación tanto de la respuesta inmune como del sistema renina angiotensina aldosterona (11).

Generalmente se manifiesta como un cuadro clínico leve, con síntomas respiratorios menores, pero hasta un 15\% de los pacientes pueden requerir hospitalización y $5 \%$ podría presentar un cuadro crítico.

La enfermedad tiene dos fases, una primera fase viral que dura alrededor de una semana y que se puede manifestar con fiebre, compromiso del estado general, cefalea, mialgias, diarrea, pérdida del sentido del olfato y del gusto. La segunda fase es la llamada inflamatoria/pulmonar, que corresponde aproximadamente a la segunda y tercera semanas de evolución y se caracteriza por compromiso pulmonar de grado variable, con aparición de disnea, hipoxemia, imágenes pulmonares características, aumento de parámetros inflamatorios sistémicos y activación de la coagulación que podrían llegar al extremo de una falla orgánica múltiple e incluso la muerte.

Los pacientes propuestos para cirugía electiva pueden haber cursado con un cuadro de COVID-19 y estar actualmente sanos o bien tener alguna condición clínica transitoria o permanente secundaria a esta infección, que puede impactar en la morbimortalidad perioperatoria. A grandes rasgos se estima que $20 \%$ del total de los pacientes COVID-19 presenta un cuadro clínico de neumonia (12), la que en un 30\% de los casos tendrá características de gravedad, pero existen manifestaciones en otros sistemas que vale la pena recordar (11).

Se ha descrito compromiso cardiaco, el que se puede ver incluso en ausencia de compromiso respiratorio, con manifestaciones tan variables como alza de troponinas, isquemia miocárdica, infarto, miocarditis, arritmias y miocardiopatía. Este compromiso cardíaco sería multifactorial y más relevante en pacientes con enfermedad cardíaca previa (13).

Las cifras de daño renal (injuria renal aguda) reportadas en pacientes hospitalizados varían entre un $0,5 \%$ a $90 \%$, dependiendo del país y de lo crítico del cuadro clínico. Las manifestaciones renales también incluyen alteraciones electrolíticas, proteinuria, hematuria y acidosis metabólica. Los mecanismos involucrados también son múltiples.

Frecuente es el compromiso hepático, observado en $19 \%$ de los pacientes, expresándose como alza de transaminasas, alza de bilirrubina y baja de albúmina sérica.

En el ámbito de la coagulación se describió un 30\% de pacientes con trombocitopenia y un 10 a $25 \%$ con cuadros catalogados de hemorragia o coagulopatía. Los fenómenos tromboembólicos arteriales o venosos, fueron descritos en un 10-25\% de todos los pacientes COVID-19 que requirieron hospitalización. En el grupo de los pacientes que requirieron UCI los cuadros trombóticos fueron más frecuentes alcanzando un 31-59\% (13).

Además, el SARS COV-2 ha sido relacionado con una variedad de manifestaciones neurológicas. Se ha descrito cefalea, pérdida del sentido del olfato y gusto, mialgias intensas, delirio, encefalitis, neuropatía inflamatoria desmielinizante, entre otros. Todos estos síntomas pueden ser parte de un compromiso multifactorial, propio del proceso inflamatorio sistémico y no muy diferente de cualquier infección viral grave. Existe poca o ninguna evidencia para atribuirlos exclusivamente a la acción directa del virus sobre el sistema nervioso central y periférico. El único síntoma que hasta este momento podría recibir una mirada diferente es la anosmia. Este síntoma tiene valor diagnóstico y se produciría por efecto del virus sobre los receptores ECA II de las células sostén del bulbo olfatorio, diferentes de las neuronas olfatorias, siendo este compromiso benigno y recuperable.

En hospitalizados con COVID-19 severo se ha descrito alguno de estos síntomas hasta en un 36\% de los pacientes (14), pero estas cifras pueden variar en el contexto ambulatorio o en cuadros menos graves.

Toda esta información sobre el cuadro clínico que produce el virus es reciente y nos debería hacer actuar con cautela, ya que aún desconocemos cuándo finaliza el proceso inflamatorio y se recuperan totalmente los pacientes o qué porcentaje evolucionará con condiciones como daño renal permanente, fibrosis pulmonar, mayor riesgo de eventos tromboembólicos, etc. Tampoco sabemos en qué momento posterior a una neumonia grave, propia de este virus, el pulmón recuperará toda su reserva funcional y estará en condiciones de recibir nuevos "insultos" como son la intubación, 
gases y la disfunción diafragmática secundaria a los relajantes pulmonares, ventilación mecánica, acto quirúrgico y dolor.

Finalmente, además hay que tener presente que de los pacientes COVID-19 que requieren hospitalización, 60-90\% tienen alguna comorbilidad de base, condición que puede empeorar posterior a la hospitalización. Las comorbilidades que más frecuentemente vemos en estos pacientes en nuestro país son la hipertensión arterial, diabetes, obesidad, asma y enfermedades cardiovasculares (2).

\section{Definición de momento oportuno en pacientes que tuvieron COVID-19}

En pacientes que tuvieron infección por SARS COV 2 y que ya están recuperados, se debe establecer una recomendación que defina el lapso de tiempo entre el término de la enfermedad y el momento más oportuno para planificar la cirugía. El objetivo de esta recomendación es disminuir el riesgo de complicaciones perioperatorias y evitar la suspensión de pacientes programados. Esta definición debería considerar la evidencia disponible junto con la opinión de expertos locales y puede variar según la institución, tipo de cirugía y características del paciente. Los pacientes se podrían categorizar según los siguientes criterios (tabla 2)

\section{1.- Pacientes asintomáticos}

Pacientes que tuvieron infección asintomática, diagnosticada sólo por PCR. Podrían someterse a cirugía electiva 14 días después de la PCR positiva.

\section{2.- Pacientes que presentaron compromiso respiratorio}

Podemos dividir a estos pacientes en 2 grupos, considerando la sintomatología y el antecedente clave de insuficiencia respiratoria (requerimiento de oxígeno suplementario):

Pacientes que no requirieron oxígeno: podrían someterse a cirugía electiva 2 semanas después del término de los síntomas. Si persisten con tos, disnea u otro síntoma deberían ser evaluados por médico broncopulmonar antes de la cirugía. No requieren nueva PCR o serología. En general se considera que los pacientes de COVID-19 excretan virus por hasta 3 semanas, por lo que este período de tiempo los convertiría en no contagiantes (15).

Pacientes que requirieron aporte de oxígeno: podrían someterse a cirugía electiva en un plazo no menor a 28 días desde el alta y una vez que hayan sido evaluados por un médico broncopulmonar. Esta evaluación debería incluir estudio con imágenes y/o pruebas de función pulmonar (estas últimas particularmente relevantes en pacientes que se presentan a cirugía torácica o abdominal alta).

¿Por qué es tan relevante esta evaluación? Porque se ha visto que después del alta existe un número importante de pacientes que por semanas o meses presenta alteraciones tanto imagenológicas como funcionales, no limitadas a los casos de neumonia grave, sino también presentes en los casos más leves (16). Los pacientes que durante la hospitalización evolucionaron con insuficiencia respiratoria se van de alta generalmente con indicación de uso de corticoides y podrían estar aún cursando con un proceso inflamatorio activo. Además tienen riesgo de evolucionar con enfermedad pulmonar difusa. Actualmente se considera a estos pacientes de "alta" (broncopulmonar) recién cuando existe resolución completa en las imágenes o mínimas lesiones en ausencia de síntomas.

En aquellos pacientes que presentaron infección respiratoria grave, requiriendo ventilación mecánica, se recomienda también una evaluación cardiológica pre operatoria. Sobre todo, si existe algún antecedente cardiovascular previo al COVID-19 o si durante la hospitalización se presentó alguna complicación cardíaca. Se ha sugerido también explorar con electrocardiograma, ecocardiograma y péptido natriurético cerebral preoperatorios.

\section{Tabla 2}

\section{3.- Pacientes que presentaron enfermedad tromboembólica}

Los pacientes que hayan cursado con cuadro de trombosis, ya sea tromboembolismo pulmonar (TEP) o trombosis venosa profunda (TVP), deben completar su periodo de anticoagulación previo a la cirugía electiva. Si ya se completó tratamiento de anticoagulación se aplicará el protocolo de tromboprofilaxis para cirugía de la institución.

No se ha recomendado un esquema excepcional de tromboprofilaxis, pero sí ser particularmente rigurosos en su cumplimiento. 


\section{4.- Pacientes que presentaron compromiso cardíaco}

COVID-19 puede producir compromiso cardíaco de formas variables. No existe a la fecha una recomendación internacional respecto de cada una, sin embargo, se sugiere que aquellos pacientes que hayan presentado cuadros de injuria miocárdica se manejen con los mismos criterios que los pacientes con infarto reciente (17).

\section{5.- Pacientes que presentaron compromiso neurológico}

No existen recomendaciones específicas en estos pacientes. Sugerimos ser criteriosos y buscar la mejor alternativa en términos de riesgo/beneficio. La Asociación Americana de Anestesia Regional (ASRA) nos entrega recomendaciones que podrían ser de utilidad a la hora de enfrentarnos con cuadros poco comunes de neuropatía inflamatoria desmielinizante (18), recordándonos que en estos pacientes se ha descrito reactivación de síntomas o una respuesta exagerada del sistema nervioso autónomo frente a la anestesia neuroaxial, por lo que su uso debe ser cauteloso.

Fuera de los plazos recomendados, no deberíamos realizar cirugía electiva, solamente deberíamos llevar a estos pacientes a pabellón para procedimientos de urgencia o no postergables. La principal razón es la morbimortalidad adicional que COVID-19 imprime durante el cuadro agudo y a la falta de información que tenemos sobre resultados en pacientes COVID-19 recientemente recuperados. Además, toda vez que se sospeche que un paciente aún es capaz de contagiar, pero la cirugía no es susceptible de postergarse, deben tomarse todas las medidas recomendadas por la $\mathrm{SACH}$ que favorezcan el aislamiento, disminuyan la posibilidad de contagio y protejan al personal de salud $(19,20)$.

\section{Rol de la Anestesia Regional}

La anestesia neuroaxial y los bloqueos periféricos se han transformado en las técnicas anestésicas y analgésicas predilectas en esta pandemia. Al no manipular la vía aérea nos permiten disminuir la generación de aerosoles y así la probabilidad de contagio hacia el personal de salud y otros pacientes (20). Por eso la consideramos la mejor alternativa anestésica en pacientes COVID-19 y no COVID-19, considerando la alta tasa de falsos negativos en el testeo con PCR. Como técnica anestésica o analgésica complementaria a la anestesia general, permiten también un mejor control del dolor, disminuyendo la necesidad de opioides y antinflamatorios no esteroidales (AINEs). Esto disminuye el número de intervenciones de enfermería, la incidencia de náuseas y vómitos y permite estadía más acotada en sala de recuperación.

En Marzo 2020 la SACH publicó recomendaciones en el ámbito de la ejecución de la anestesia regional y manejo peri-operatorio, destinadas a mantener el estándar de seguridad de los pacientes, previniendo el contagio de pacientes y personal médico. Dentro de los objetivos de estas recomendaciones están la realización de una adecuada selección, preparación y ejecución de la anestesia regional, como también sugerencias de conductas postoperatorias. Estas recomendaciones abarcaron desde el uso de equipo de protección personal (EPP) en este contexto, sugerencias de sedación, precauciones específicas en pacientes COVID-19, hasta consideraciones específicas en determinados bloqueos de dosis única y continuos (20).

A continuación, resumiremos las ventajas de la anestesia regional en el contexto actual, considerando el menor riesgo de contagio, mejores resultados clínicos en términos de dolor, eficiencia del sistema y beneficios económicos. También repasaremos algunas consideraciones específicas, que pueden favorecer el éxito de la técnica y evitar complicaciones.

\section{¿Cuáles son las ventajas de la anestesia regional en el contexto COVID-19?}

Disminuye la generación de aerosoles toda vez que evita la manipulación de la vía aérea, intubación y extubación. La mayor parte de las veces estos procedimientos pueden ser llevados a cabo con precaución de gotas, lo que significa ahorro de EPP. Se ha sugerido elevar a precaución de aerosoles al realizar bloqueos en zonas cercanas a la cabeza y cuello del paciente, por mayor exposición

Disminuye el riesgo de contagio del personal (21)

Utiliza menor cantidad de drogas para sedación e hipnosis que la anestesia general, lo que representa un alivio frente a la frecuente escasez

Requiere de menor preparación de drogas y equipos que una anestesia general

Se asocia a una reducción de un $20 \%$ de costos en salud, comparado con la anestesia general (22) 
Los bloqueos de nervio periférico se asocian a menor tiempo de estadía en sala de recuperación por mejor manejo del dolor y más rápida recuperación de conciencia. Algunos pacientes podrian irse directo a su habitación si el protocolo institucional lo permite

Disminuye los riesgos asociados a intubación orotraqueal, acción de relajantes musculares y ventilación mecánica que existen en pacientes sanos y más aún en pacientes con un pulmón con menor reserva

Las técnicas regionales periféricas se asocian a un menor número de intervenciones por enfermería en sala de recuperación

La técnicas periféricas continuas merecen una mención especial, puesto que permiten el control del dolor en aquellas cirugías con alto requerimiento analgésico por más de 24 horas, lo que permite menor número de días de hospitalización o cirugía francamente ambulatoria

Disminuiría el riesgo de contagio de personal y otros pacientes en la sala de recuperación por menor tos residual comparado con pacientes que recibieron anestesia general

\section{¿Cuáles son las desventajas de la anestesia regional en el contexto COVID-19?}

Necesita mayor tiempo para ser realizada, anestesiólogo entrenado y equipo de trabajo afiatado. Para obtener bloqueos quirúrgicos y no solo analgésicos se requiere esperar un tiempo mínimo de latencia, dependiente de cada bloqueo

Requiere de un paciente que idealmente consienta, colabore con el procedimiento y no esté sintomático desde el punto de vista respiratorio (tos)

Supone que la cirugía sea altamente factible de realizar de principio a fin con la técnica regional, ya que el peor escenario es la conversión intraoperatoria a anestesia general. Siempre se sugiere evaluar el éxito del bloqueo para evitar conversión inesperada a anestesia general

Requiere de una reserva respiratoria que permita tolerar el decúbito supino, manteniendo SpO2 basal mayor a 93\% y requiriendo flujos bajos de oxígeno para evitar generación de aerosoles (22)

Requiere de un adecuado estado de la coagulación para anestesia neuroaxial y bloqueos regionales profundos o áreas no compresibles, por lo que debería descartarse trombocitopenia relevante o alteraciones de la coagulación secundarias cuando nos encontremos frente a un cuadro inflamatorio sistémico

\section{Para finalizar vale la pena enfatizar dos situaciones:}

Toda vez que nuestro paciente tenga comprometida la función pulmonar, debemos evitar los bloqueos que comprometan al nervio frénico, como son los bloqueos de plexo en abordaje supraclavicular e interescalénico. Aún no se han descrito reales dosis o concentraciones de anestésico local que permitan evitar este efecto colateral

En pacientes con neuropatías inflamatorias desmielinizantes secundarias al cuadro de COVID-19 recomendamos evitar el uso de bloqueos de nervio periférico, especialmente si estas están aún en evolución y no existe una sintomatología estable

\section{Comentario final}

En el curso de los últimos meses hemos aprendido a implementar conductas y estrategias rígidas de protección, pero que a la vez han puesto a prueba nuestra flexibilidad y capacidad de rearticulación como profesionales de la salud. Una de estas estrategias fue la suspensión de la cirugía electiva y ahora nos toca retomarla con prudencia y seguridad, considerando además a un grupo "nuevo" de pacientes. La recomendación actual es retomar la cirugía electiva gradualmente, considerando características del procedimiento, de los pacientes y de las instituciones. En este contexto la anestesia regional posee beneficios en relación con riesgo de contagio, resultados clínicos, beneficios económicos y eficiencia del sistema. 


\section{Anexo}

\section{Tabla 1}

Recomendación para reanudación escalonada

\begin{tabular}{c|c|c|c|}
\hline Prioridades/Etapas & 1era & 2da & 3era \\
\hline Tiempo de Cirugía & menos 3 hr & más de 3 hr & más de 3 hr \\
\hline Días hospitalización & $0-2$ & $2-3$ & 4 y más \\
\hline Edad & $<65-70$ años & $>65-70$ años & $>70$ años \\
& $>1$ año & $>6$ meses & $>1$ mes \\
\hline ASA & I o II & I o II & I-IV \\
\hline IMC & $<30$ & $<30$ & $>30$ \\
\hline
\end{tabular}

Tabla 2

Recomendación para programar cirugía electiva

\begin{tabular}{c|c|c|}
\hline $\begin{array}{c}\text { Cuadro clínico } \\
\text { presentado }\end{array}$ & $\begin{array}{c}\text { Programación de cirugía } \\
\text { electiva }\end{array}$ & $\begin{array}{c}\text { Exámenes COVID } \\
\text { necesarios }\end{array}$ \\
\hline Asintomático & 15 días desde PCR (+) & No requiere \\
\hline Sintomático Leve & $\begin{array}{c}\text { 15 días desde el fin de } \\
\text { síntomas }\end{array}$ & No requiere \\
\hline $\begin{array}{c}\text { Neumonia con } \\
\text { requerimiento de O2 o } \\
\text { aún sintomático }\end{array}$ & $\begin{array}{c}\text { Control por } \\
\text { broncopulmonar al mes } \\
\text { de alta }\end{array}$ & $\begin{array}{c}\text { Rx o TAC de tórax según } \\
\text { indicación de médico } \\
\text { broncopulmonar }\end{array}$ \\
\hline
\end{tabular}

\section{Bibliografía}

1.Diaz A, Sarac B, Schoenbrunner A y cols. Elective surgery in the time of COVID-19. Amjsurg 16/04/2020. Vol 219;6:900-902

2.Reporte diario Coronavirus Ministerio de Salud Chile. https:/www.gob.cl/coronavirus/cifrasoficiales/

3.Doglietto F,Vezzoli M, Gheza F y cols. Factors Associated with Surgical Mortality and Complications Among Patients With and Without Coronavirus Disease 2019 (COVID-19) in Italy. Jamasurg. 2020 E1-12. Acceso disponible desde 12 de Junio 2020. doi:10.1001/jamasurg.2020.2713 
4.Banghu A, Nepogodiev D, Glasbey J y cols. Mortality and pulmonary complications in patients undergoing surgery with perioperative SARS-CoV-2 infection: an international cohort study

Lancet, Published Online

May 29, 2020 https://doi.org/10.1016/ S0140-6736(20)31182-X See Online/Comment https:/doi.org/10.1016/ S0140-6736(20)31256-3

5.Recomendaciones para iniciar o aumentar la actividad quirúrgica elective durante la pandemia COVID-19 en los hospitals públicos de Chile. Sociedad de Anestesiología de Chile. 06/05/2020. www.sachile.cl

6.COVID-19: Guidance for triage of non-emergent surgical procedures. American College of surgeons. Disponible en: https://www.facs.org/covid-19/clinical- guidance/triage; 2020. 02/04/2020.

7.The ASA and APSF Joint Statement on Perioperative Testing for the COVID-19 Virus. April 29,2020.

8.Zhao J, Yuan Q, Wang $\mathrm{H}$ y cols. Antibody responses to SARS-CoV- 2 in patients of novel coronavirus disease 2019. Clinical Infectious Diseases. 2020.

9.S Lauer, K Grantz, Q. Bi y cols. The incubation period of coronavirus disease 2019 (COVID- 19) from publicly reported confirmed cases: estimation and application, Ann. Intern. Med. (2020), https://doi.org/10.7326/m20-0504.

10.Puelles V, Lütgehetmann M, Lindenmeyer M y cols. Multiorgan and renal tropism of SARS-CoV-2. N. Engl. J. Med. https://doi.org/10.1056/NEJMc2011400 (2020).

11.Gupta A, Madhavan M, Sehgal K y cols. Extrapulmonary manifestations of COVID-19. Nat Med 07/2020;26(7) 1017-1032. doi:0.1038/s41591-020-0968-3.

12.Shi Y, Wang G, Cai X y cols. An overview of COVID-19 J Zhejiang Univ-Sci B (Biomed \& Biotechnol) 2020 21(5):343-360. doi: 10.1631/ zus.B2000083. Epub 2020 May 8.

13.W Wiersinga, A Rhodes, A Cheng y cols. Pathophysiology, Transmission, Diagnosis, and Treatment of Coronavirus Disease 2019 (COVID-19). A Review. JAMA. 2020;324(8):782-793. doi:10.1001/jama.2020.12839

14.Mao L, Jin H, Wang M y cols. Neurologic manifestations of hospitalized patients with Coronavirus Disease 2019 in Wuhan China. JAMA Neurol. 2020 Apr 10;77(6):1-9. doi: 10.1001/jamaneurol.2020.112

15.Qian GQ, Chen XQ, LV DF y cols. Duration of SARS-COV-2 viral shedding during COVID-19 infection Infect Dis (Lond) $2020 \mathrm{Jul} ; 52$ (7):511-512 doi10.1080/23744235.2020.1748705

16.Mo X, Jian W, Su Z y cols. Abnormal pulmonary function in COVID-19 patients at time of hospital discharge. Eur Respir J 2020;55:2001217

17.Fleisher L, Fleischmann K, Auerbach A y cols. 2014 ACC/AHA Guideline on Perioperative Cardiovascular Evaluation and Management of Patients Undergoing Noncardiac Surgery. J Am Coll Cardiol. 2014. PMID: 25091544

18.Neal J, Barrington M, Brull R y cols. The Second ASRA Practice Advisory on Neurologic Complications Associated With Regional Anesthesia and Pain Medicine: Executive Summary 2015. Reg Anesth Pain Med Sep-Oct 2015;40(5):401-30.doi 10.1097/AAP.0000000000000286

19.Recomendaciones SACH manejo pacientes COVID. Sociedad de Anestesiología de Chile 16/03/2020. www.sachile.cl

20.Recomendaciones para la ejecución de anestesia regional no obstétrica en perioperatorio de pacientes COVID-19. Sociedad de Anestesiología de Chile 2020. www.sachile.cl

21.Tran K, Cimon K, Severn M y cols. Aerosol generating procedures and risk of transmission of acute respiratory infections to healthcare workers: a systematic review. PLoS One 2012; 7: e35797.

22. Ashokka B Y, Chakraborty A, Subramanian B y cols. Reconfiguring the scope and practice of regional anesthesia in a pandemic: the COVID-19 perspective. Reg Anesth Pain Med 2020;45:536-543. doi:10.1136/rapm-2020-101541 